Original Article

\title{
FORMULATION AND EVALUATION OF OPTIMISED MALTODEXTRIN BASED PRONIOSOME POWDERS CONTAINING BAZEDOXIFENE ACETATE FOR ORAL DELIVERY
}

\author{
SMITHA GANDRA* \\ *Department of Pharmaceutics, Marathwada Mitra Mandal's College of Pharmacy, Thergoan, Pune, Maharashtra, India \\ Email: smithagandra@yahoo.com
}

Received: 10 Jul 2020, Revised and Accepted: 08 Sep 2020

\begin{abstract}
Objective: The main objective of the present study was to develop proniosomal formulations to enhance the oral bioavailability of bazedoxifene acetate by improving solubility, dissolution and/or intestinal permeability.

Methods: Proniosomal powder formulations were prepared with bazedoxifene acetate drug varying the span 40 and cholesterol ratio in the range of 0.8:0.2 to 0.2:0.8 using maltodextrin as a carrier by slurry method. The prepared proniosomal powder was filled into capsules. The bioavailability enhancement of proniosomes loaded with drug was studied focusing on non-ionic surfactants composition and drug: span 40 ratio. Prepared proniosomes were characterized for their particle size distribution, zeta potential, entrapment efficiency, in vitro dissolution study and thermal characteristics to understand the phase transition behavior. Further, the formulated proniosomes were subjected to stability behavior, ex vivo permeation studies using rat intestine followed by in vivo studies.
\end{abstract}

Results: Physico-chemical studies help in the optimization of formulations. Enhancement in dissolution is due to the incorporation of bazedoxifene acetate into the non-ionic surfactant and change in the physical state from crystalline to amorphous, thus improving oral bioavailability. Ex vivo studies show significant permeation enhancement across the gastrointestinal membrane compared to control.

Conclusion: In conclusion, proniosomes provide a powerful and functional way of the distribution of inadequately soluble bazedoxifene acetate drug, which is proved from in vivo studies based on the enhanced oral delivery.

Keywords: Proniosomes, Niosomes, Permeability, Pharmacokinetics, Bioavailability

(c) 2020 The Authors. Published by Innovare Academic Sciences Pvt Ltd. This is an open access article under the CC BY license (http://creativecommons.org/licenses/by/4.0/) DOI: http://dx.doi.org/10.22159/ijcpr.2020v12i6.40285. Journal homepage: https://innovareacademics.in/journals/index.php/ijcpr

\section{INTRODUCTION}

The improvement of oral extent of absorption for poorly or inadequately aqueous soluble active pharmaceutical ingredient is still the most crucial and demanding feature in the development of dosage forms. Curative success of a drug relies upon the extent and rate to which the drug is absorbed and thus upon the amount of solute that enters in a unit volume of the solvent of drug molecule to show the pharmacological action. The premier method of evaluating therapeutic success of drugs with a low solubility is by checking bioavailability. The conventional techniques of improving the bioavailability act by enhancing the dissolution behaviour [1] such as reducing the particle size by co-grinding technique [2], crystal modification [3], micronization [4] but can't preclude or alter the gastrointestinal (GI) tract barrrier function and presystemic metabolism. Along with above some more disadvantages add to the list such as particulate aggregates formation, toxicity from vehicles, relatively high cost of production, poor loading of the drug, GI tract irritation caused from high concentration of excipients and low stability of developed dosage form $[5,6]$.

Hence to overcome all such difficulties encapsulation of the drug in vesicular structures [7] in the form of pharmacosomes, liposomes [8], niosomes [9], cubosomes, transferosomes are one such system, which can be expected to prolong the duration of the drug in systemic circulation, and reduce the toxicity by selective uptake along with lymphatic transport thus leading to improved permeation [10] along with rate and extent of absorption by avoidance of first pass metabolism [11]. However, they suffer from a number of important drawbacks that have prevented its widespread use. Niosomes [12] which are comparitively stable chemically and cheap in price because of usage of surfactants instead of phospholipids used in liposomes face physico-stability problems namely sedimentation of particles leading to fusion and aggregation and also leakage of drug upon storage.
In order to improve the stability of vesicular systems [13] and circumvent all of the complications, a modern contemporary technique to produce vesicular systems, Provesecular system was introduced without altering or affecting intrinsic properties of the drugs entrapped. Provesicular systems [14] namely proliposomes and proniosomes consist of phospho-lipids or non-ionic surfactants loaded with drug respectively; along with readily aqueous soluble carrier (porous in nature). Proniosomes [15-17] are defined as vesicles composed of actively pharmaceutical ingredient with readily aqueous soluble carrier that is coated with surfactant (nonionic) to form dry, free-flowing product. Thus, upon contact with sterilized water, which helps in generation or emergence of niosomes from proniosomes eliminates many physical steadiness difficulties associated with niosome dispersions. With the benefits of firmness during sterilization, measuring, transfer, distribution and storage proniosomes became a versatile system for the delivery of numerous drugs $[18,19]$.

Bazedoxifene acetate, a novel third-generation Selective Estrogen Receptor Modulator (SERM) is used in the prevention and treatment of postmenopausal osteoporosis [20]. An ideal SERM used for treatment of postmenopausal osteoporosis should avoid fractures controlling bone loss; decrease the risk of both cancers endometrial and breast. It should also provide comfort and calmness from symptoms associated with menopause without increasing the risk of thrombosis and coronary heart disease [21]. Bazedoxifene is processed to have beneficial effects on lipid and bone with minimum stimulation of breast or uterine tissues [22]. Bazedoxifene mechanism of action involves adhering to ER in tissues of bone as agonist promoting bone mineral and density preservation [23]. In the similar manner, bazedoxifene acetate acts as antagonist, the tissue in uterine and breast thus preventing stimulation and proliferative action [24]. To the best of our knowledge, no articles are available in literature on proniosomes of bazedoxifene acetate and henceforth, an attempt was made to focus on the main objective 
of research work which is to formulate and evaluate and study the enhancement in intestinal absorption and bioavailability. Solid state characterization helps in investigating the morphology and physical state. Further ex vivo and in vivo studies were carried out to access the permeation of drugs from proniosomes using rat intestine and improvement in oral bioavailability from pharmacokinetic studies in rats, respectively.

\section{MATERIALS AND METHODS}

Animal studies for both ex vivo and in vivo experiments were conducted at Albino research center (Registration No. 1722/RO/Ere/S/13/CPCSEA) with prior approval of the institutional animal ethical committee. Euthanasia and disposal of the carcass were in accordance with the guidelines.

Bazedoxifene acetate was a kind gift sample from MSN labs, Hyderabad, India. Span and Cholesterol (>99\%) procured from Sigma, St. Louis, Missouri, United States of America. Maltodextrin was a generous gift sample from Dr. Reddy's laboratories, Hyderabad. All other chemicals were of analytical grade and solvents were of HPLC grade. Freshly collected double distilled water was used all through the experiment.

\section{Formulation of proniosomes}

Essential components of proniosomes used in the formulation are non-ionic surfactants acting as permeability enhancers, carrier or coating material and membrane stabilizers. Among the carriers, maltodextrin and sorbitol are available in the preparation of proniosomes. Maltodextrin usage as carrier in preparation of proniosomes permits stretchability in the incorporation of surfactant and other ingredients at various ratios. Sorbitol usage results in the formation of mass that is like solid cake [25]. Nonhygroscopicity and compatibility with drugs are added advantages with maltodextrin. Finally, efficient rehydration is the outcome when the surfactant is coated as a thin coat, which is made possible by maltodextrin because of its high surface area and preserved morphology [26].

The maximum benefit of proniosomal systems can be achieved when it forms stable niosomes with high entrapment efficiency after hydration in the gastric fluids. Cholesterol, structural lipid helps in accentuating the entrapment of drugs preventing it leakage by stabilising the bilayered membrane. Though lecithin is other alternative for cholesterol as a membrane stabiliser, lecithin is not widely used as it imparts lesser stability when measured against cholesterol [25].

Proniosomes were prepared varying the non-ionic surfactant and cholesterol ratios in the range of 0.8:0.2 to 0.2:0.8 using maltodextrin as carrier assigning the codes for various formulations. All surfactants used were in excess of their critical micelle concentrations. In the present invention among the spraying method, coacervation phase separation method and slurry method for preparation of proniosomes; slurry technique or process [25] is adapted and the composition is represented in table 1.

Table 1: Composition for bazedoxifene acetate loaded proniosome powder using maltodextrin

\begin{tabular}{|c|c|c|c|c|c|}
\hline Formulation code & API (mg) & Maltodextrin (mg) & Molar ratio (SPAN40:CHOL) & SPAN 40 (mg) & Chol (mg) \\
\hline $\mathrm{BPNS}_{1}$ & 10 & 250 & $0.8: 0.2$ & 80.4 & 19.3 \\
\hline $\mathrm{BPNS}_{2}$ & 10 & 250 & 0.7:0.3 & 70.4 & 28.9 \\
\hline $\mathrm{BPNS}_{3}$ & 10 & 250 & $0.6: 0.4$ & 60.3 & 38.6 \\
\hline $\mathrm{BPNS}_{4}$ & 10 & 250 & $0.5: 0.5$ & 50.3 & 48.2 \\
\hline $\mathrm{BPNS}_{5}$ & 10 & 250 & $0.4: 0.6$ & 40.2 & 57.9 \\
\hline $\mathrm{BPNS}_{6}$ & 10 & 250 & $0.3: 0.7$ & 30.2 & 67.5 \\
\hline $\mathrm{BPNS}_{7}$ & 10 & 250 & $0.2: 0.8$ & 20.1 & 77.2 \\
\hline
\end{tabular}

API-active pharmaceutical Ingredient (Bazedoxifene acetate drug)

\section{Evaluation/Characterization of proniosomes}

\section{Hydration of proniosomal systems}

Hydration of Proniosomal systems is judged by studying the form, shape and structure of the niosomes formed from the proniosomes by optical microscopy (Olympus-CH20i). Procedure involves the addition of small or little quantities of water onto a cavity glass slide where the proniosome powder was taken. Under an optical microscope, the formation of niosomes was monitored and photomicrograph was taken.

\section{Measurement of micromeritic properties of proniosomal systems}

Micromeritic properties are assessed by flow properties of powder which are vital in handling and processing operations and for further dosage form development. Flow properties are reviewed from the angle of repose [27] studied by the fixed-funnel technique [28]. Briefly, proniosome powder was poured into a funnel which was fixed at a position so that the $13 \mathrm{~mm}$ outlet orifice of the funnel is $10 \mathrm{~cm}$ above a level black surface. The powder flowed down from the funnel to form a cone on the surface, and the angle of repose was then calculated by measuring the height of the cone and the diameter of its base. And also Carr's index and Hausner's ratio are obtained from bulk and tapped density calculations [29].

Determination of the size of niosomes, zeta potential, entrapment efficiency and number of niosomes

For quantifying these parameters, proniosome powders are to be converted into niosome dipersions, which are obtained by hydration followed by $3 \mathrm{~min}$ bath sonication (Soltec $2200 \mathrm{MH}$, India). For the thus formed niosomes average size and its distribution is checked by
Nanoparticle Analyzer (Horiba SZ-100, Japan). The principal behind which is spectroscopic technique by photon correlation approach. Smoluchowski equation method is used to check zeta potential [30].

$$
\zeta=\mathrm{UE \eta} / \varepsilon
$$

Where ' $\zeta$ ' is zeta potential, 'UE' is electrophoretic mobility, ' $\eta$ ' is the viscosity of the medium, and ' $\varepsilon$ ' is dielectric constant.

After suitable dilution of proniosomes with freshly collected double distilled water, the samples are proceeded for further analysis. Niosome size and Polydispersity Index (PI) of formed niosomes were obtained directly from the Nanoparticle Analyzer and Zeta Sizer equipment and entrapment efficiency from earlier mentioned and reported ultra-filtration technique which was carried out using Centrisart (Sartorius AG Gottingen, Germany) equipment [31]. \% Entrapment efficiency is obtained by subtracting unentrapped drug from the total amount of drug.

Provesicular formulations are optimized based on the number of vesicles formed after the hydration. The niosomes formed after hydration of proniosome powder were counted by an optical microscope (Olympus $\mathrm{CH} 20 \mathrm{i}$, India) using a hemocytometer, and the number of niosomes per cubic $\mathrm{mm}$ was calculated by using the following formula [31].

Total number of niosomes per $\mathrm{mm}^{3}$

Total number of niosomes counted $\times$ dilution factor $\times 4000$ Total number squares counted

\section{In vitro dissolution study}

In vitro dissolution studies (Lab India DS 8000, India) for proniosome powders (filled in capsule dosage form) compared 
against control (filled in capsule dosage form) are performed in USP type-I (basket) apparatus containing $900 \mathrm{ml}$ of dissolution medium $(\mathrm{pH} 1.2$ simulated gastric fluid) kept at a controlled temperature of $37 \pm 0.5{ }^{\circ} \mathrm{C}$ for which the basket speed is set at $50 \mathrm{rpm} .5 \mathrm{ml}$ sample was removed, maintaining the sink conditions at definite time points, filtered through $0.45 \mu \mathrm{m}$ millipore membrane filter prior to analysis and drug release was analyzed by U. V Visible Spectrophotometer (Lab India UV 3000+, India), determining the absorbance at $299 \mathrm{~nm}$ for bazedoxifene acetate [32].

\section{Scanning electron microscopy (SEM)}

By SEM (Hitachi S-3700N, Japan) technique morphology of surface for both the pure drugs, and developed optimized proniosomes was identified [33]. Scanning electron microscopic images or pictures are taken at an accelerating voltage of $15 \mathrm{keV}$. Upon brass stub samples are made to adhere with the help of adhesive tape (double-sided), followed by slender layer gold coating upon sample makes it electrically conductive, which is prerequisite for observing and taking images.

\section{Transmission electron microscopy (TEM)}

TEM (JEOL-100CX-II, Tokyo, Japan) technique also helps in knowing the form, shape and structure of samples as in SEM but in more detail. Prior to the observation of samples, upon a copper grid (coated with carbon) sample, lean film is to be negatively stained using $0.2 \% \mathrm{w} / \mathrm{v}$ solution of sodium phosphotungstate left for air drying; followed by imaging [34].

\section{Differential scanning calorimetry (DSC)}

DSC (Shimadzu 60H, Tokyo) analysis of optimized formulation and pure drug are studied for the molecular state of the compound. DSC curves help in deducing heat of fusion and melting point. Approximately $5 \pm 2 \mathrm{mg}$ of sample is taken in a sealed pan (hermetically) made of aluminum and gradually exposed to a temperature at $10^{\circ} \mathrm{C}$. min- 1 heating rate from $20^{\circ}-300^{\circ} \mathrm{C}$ under gas $\left(\mathrm{N}_{2}\right)$ flow at a constant rate of $30 \mathrm{ml}$. min-1.

\section{Powder X-ray diffractometry (PXRD)}

The PXRD (Shimadzu 7000, Tokyo) repeated format for both drugs and most effective powder formulations are received at a voltage of 45kilovolts; when a beam of $\mathrm{Cu} \mathrm{K} \alpha$ radiation, generated from 40milliAmperes current moves forward through $\mathrm{Ni}$ filtered monochromator made up of graphite onto the detector. All samples were run at $1^{\circ}(2 \theta) \mathrm{min}^{-1}$ from $3^{\circ}$ to $45^{\circ}(2 \theta)$.

\section{Fourier transform infrared spectroscopy (FT-IR)}

IR spectra of drug, best powder formulation and excipients such as maltodextrin are acquired from FT-IR spectrophotometer (Shimadzu 8400S, Japan) at a scanning range of $4000-400 \mathrm{~cm}^{-1}$ with a resolution of $4 \mathrm{~cm}^{-1}$ to study the drug-excipient interactions. The sample for which is prepared following the potassium bromide $(\mathrm{KBr}$ pellet) procedure.

\section{Stability studies}

Stability for the best formulations is studied for a period of $180 \mathrm{~d}$ for various parameters such as particle size of niosomes formed from proniosome, percentage retention of drug and ex vivo permeation across rat intestine. At predetermined time points that is $0,30,60,90,120$ and $180 \mathrm{~d}$ samples kept at $24 \pm 2{ }^{\circ} \mathrm{C}$ and $4 \pm 2{ }^{\circ} \mathrm{C}$ in aluminum foil-covered glass vials are taken out hydrated, looked for crystal formation of the drug under the microscope (optical) and also for above-mentioned parameters.

\section{Ex vivo absorption study using rat intestine}

Albino wistar rats (male) approximately weighing 200 gm are taken. The animals were housed in separate cages in a clean room and maintained under controlled condition of temperature and the rats had free access to food and water. Before ex vivo absorption study experiments, the rats fasted overnight with free access to water were sacrificed by ether inhalation technique. An incision was made through a midline to expose the abdominal content. $10 \mathrm{~cm}$ of small intestine (ileum) segment used for the study was collected and flushed with freshly prepared Krebs Ringer solution to clean intestine so that it is free from mucus and all adhered contents. Into the ileum, which was tightly closed at one end, proniosome dispersion $(0.5 \% \mathrm{w} / \mathrm{v}$ PEG200) equivalent to $2 \mathrm{mg}$ of drug was introduced and further closed tightly on another end. The tissue was immersed into a continuously aerated organ bath further into receptor compartment consisting of $250 \mathrm{ml}$ of phosphate buffer ( $\mathrm{pH}$ 6.8) maintained at $37 \pm 0.5^{\circ} \mathrm{C} .5 \mathrm{ml}$ sample was withdrawn at definite time intervals and sink conditions are maintained and are further analysed. Control (drug dispersion equivalent to $2 \mathrm{mg}$ ) and proniosomal systems are compared [35]. The cumulative amount of drug permeated was plotted against time. The steady-state flux was calculated from the slope of linear portion of the cumulative amount permeated per unit area vs. time plot. The enhancement ratio was calculated by dividing the flux of formulation with flux of control.

\section{In vivo bioavailability studies}

High-performance liquid chromatography (HPLC-Waters separation module-Model No: 2690; Detector: PDA-Model No: 2996, USA) method is developed and validated for the estimation of respective sample drug in serum [36].

\section{Sample analysis}

Bazedoxifene acetate was quantitatively determined in serum by HPLC using 60:40(v/v) potassium dihydrogen orthophosphate and acetonitrile respectively $\mathrm{pH}$ adjusted to 3.0 using orthophosphoric acid, as mobile phase at a flow rate of $1.0 \mathrm{ml} / \mathrm{min}$ equipped with LC10 AT solvent delivery unit. A $C_{8}$ reverse-phase stainless steel analytical column $(150 \times 4.6 \mathrm{~mm})$ withur particle size was employed for chromatographic separation (Hypersil BDS). The column eluent was monitored at a wavelength of $299 \mathrm{~nm}$ using a PDA detector, and the sensitivity was set at 0.005 AUFS at ambient temperature. The serum samples were processed by the protein precipitation method. Briefly, $100 \mu \mathrm{l}$ of serum sample was treated with $100 \mu \mathrm{l}$ of internal standard $(1 \mu \mathrm{g} / \mathrm{ml}$ of raloxifene hydrochloride in methanol) and vortexed (Remi Equipments, India) for $1 \mathrm{~min}$. The drug was extracted with $0.2 \mathrm{ml}$ of acetonitrile, vortexed for $10 \mathrm{~min}$ followed by centrifugation at 4000 rpm for $15 \mathrm{~min}$ and the separated organic layer was injected onto the HPLC $(20 \mu \mathrm{l})$. The limit of detection and quantification were 10 and $30 \mathrm{ng} / \mathrm{ml}$, respectively. The concentration vs. peak area ratio plot was linear $\left(r^{2}>0.99\right)$ over the concentration range of interest (standard preparation), and the bazedoxifene acetate content in samples was quantified using this plot.

\section{Pharmacokinetic study}

Albino wistar rats (male) approximately weighing $200 \mathrm{gm}$ are selected for these investigations, which are fasted for overnight. These wistar rats are split up into 2 groups with 6 in every group and delivered with each treatment at a random basis. Two group includes one for control (pure drug-oral suspension) and one for optimized proniosome formulation. Accurately weighed dose of 10 mg per kg body weight the drug or optimized formulation are administered. $250 \mu \mathrm{l}$ of blood sample is taken or withdrawn into microcentrifuge tubes retro-orbital plexus at definite time points. Serum was obtained from the collected blood, which was left to clot by centrifugation process for $10 \mathrm{~min}$ at $10,000 \mathrm{rpm}$ using a centrifuge (Remi R-24, India). Thus, obtained drug-containing serum is stored at a temperature of $-20^{\circ} \mathrm{C}$ until further analysis.

\section{Calculation of pharmacokinetic parameters}

Cmax and Tmax are picked up from the graph plotted between concentrations of drug in serum at various time points. Trapezoidal rule technique is followed to determine $\mathrm{AUC}_{0-\mathrm{t}}$. In the same way $\mathrm{AUC}_{\mathrm{t}-\infty}$ was calculated by dividing the concentration of the drug at last time point in the serum with Ke. The relative bioavailability was estimated by dividing the $\mathrm{AUC}_{0-\infty}$ of proniosome formulation with control oral suspension.

\section{Statistical analysis}

The data obtained were subjected to student's's' test and one-way analysis of variance (ANOVA), and the significance of the difference between formulations was calculated by student-Newman-Keuls 
(compare all pairs) with Instant Graphpad prism software (version 4.00; GraphPad Software, San Diego California). The level of statistical significance was chosen as $\mathrm{p}<0.05$.

\section{Ex vivo/In vivo correlation}

Ex vivo/In vivo Correlation was performed by determining the $\mathrm{r}^{2}$ value from the graph plotted between the AUC of In vivo and ex vivo concentration at different time points [37].

\section{RESULTS AND DISCUSSION}

\section{Preparation of proniosome powders}

In the present study, proniosomes are formulated, developed and assessed for their scope in raising the quality of the delivery of bazedoxifene acetate drugs by oral route. Accurately weighed amounts using weighing balance (sartorius TE 124S, Germany) for mixture $(250 \mu \mathrm{M})$ containing different types of spans and cholesterol at diversified molar ratios (0.8:0.2, 0.7:0.3, 0.6:0.4, 0.5:0.5, 0.4:0.6, $0.3: 0.7,0.2: 0.8)$ and active component or ingredient $(10 \mathrm{mg})$ were solubilised in $20 \mathrm{ml}$ of chloroform and methanol (2:1). The formed mixture was shifted into $250 \mathrm{ml}$ flask with round bottom and upon addition of maltodextrin $(250 \mathrm{mg})$, slurry was formed. The roundbottomed flask was connected to a rotary vaccum evaporator (Rotavap PBU-6, India) to remove the organic solvent by evaporation process at low pressure and $45 \pm 2{ }^{\circ} \mathrm{C}$ temperature with
60 to 70rpm. Complete removal of organic solvent results in dry products and leaving it in a vacuum oven at $24{ }^{\circ} \mathrm{C}$ for a night further makes the product free-flowing. Thus, acquired proniosome powders are kept in glass vial at $4{ }^{\circ} \mathrm{C}$, which can be delivered in the form of capsules. For comparison, control formulation devoid of spans and cholesterol was processed.

Niosomes are formed from proniosomes immediately upon contact with water at in vitro conditions or with body fluids at in vivo conditions, which is considered to be achieved without great effort when compared with traditional technique of preparation of niosomes by dry-film procedure as plan of work involves tedious shaking process to absorb water by surfactants. Thus, the production from proniosomes is considered as the greatest advantage i.e., eases of use.

\section{Evaluation/Characterization of proniosomes}

Evaluation of proniosomes after preparation aids in characterizing the formulation and identifying the optimized formulation [38-40].

\section{Hydration of proniosome systems}

Upon hydration of proniosomes, niosomes were derived and were formed immediately upon contact with water and the photomicrographic images at different magnifications are represented in fig. 1 .
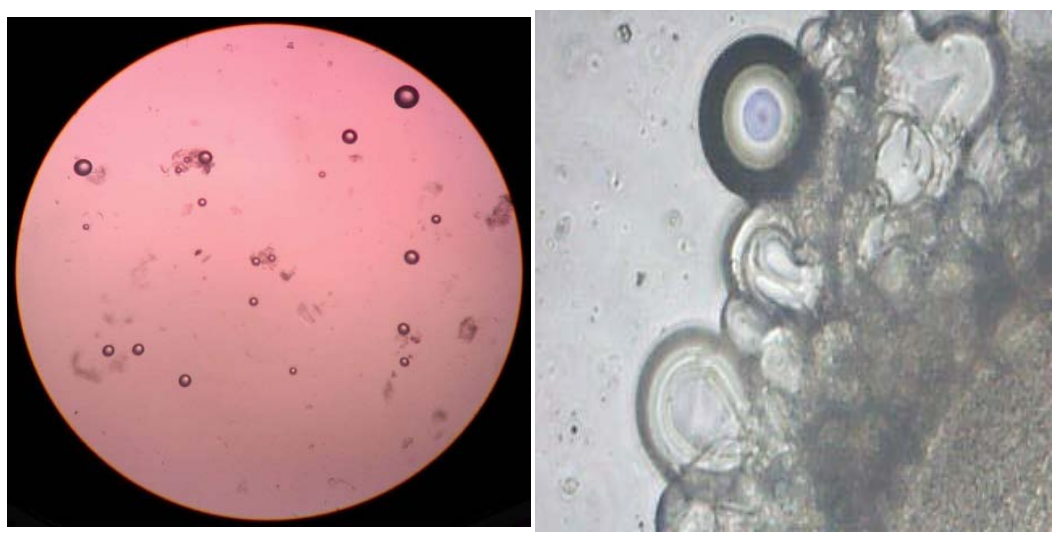

Fig. 1: Photomicrographic Images of formation of niosomes from proniosomal systems under magnification 10X and 450X

\section{Measurement of micromeritic properties of proniosome systems}

The measurement of flow properties of the proniosome powders plays key role as it values helps in various operations during manufacturing of a dosage form such as ease with which the powders are filled into the container and uniformity of the dose.

Angle of repose, Carr's compressibility index and Hausner's ratio results help in evaluating flow measurements. Cohesion or Internal friction between the particles is dependent on the angle of repose values which are directly proportional to each other. Therefore, smaller the angle of repose values $\left(24^{\circ}\right)$ better will be the flow properties. This is strengthened by Carr's compressibility index values which are less than 20 and Hausner's ratio which are less than 1.30 [27] and the results are indicated in table 2. All the formulations were having excellent flow property considering the angle of repose.

Table 2: Flow properties of various proniosomal formulations

\begin{tabular}{|c|c|c|c|}
\hline Formulation code & Angle of repose* & Compressibility index ${ }^{*}$ & Hausner's ratio* \\
\hline $\mathrm{BPNS}_{1}$ & $21.28 \pm 0.12$ & $17.60 \pm 0.20$ & $1.20 \pm 0.16$ \\
\hline $\mathrm{BPNS}_{2}$ & $22.94 \pm 0.18$ & $20.20 \pm 0.09$ & $1.30 \pm 0.06$ \\
\hline $\mathrm{BPNS}_{3}$ & $23.09 \pm 0.13$ & $12.70 \pm 0.14$ & $1.21 \pm 0.03$ \\
\hline $\mathrm{BPNS}_{4}$ & $22.66 \pm 0.20$ & $13.06 \pm 0.13$ & $1.22 \pm 0.04$ \\
\hline $\mathrm{BPNS}_{5}$ & $22.63 \pm 0.14$ & $13.09 \pm 0.19$ & $1.10 \pm 0.05$ \\
\hline $\mathrm{BPNS}_{6}$ & $23.84 \pm 0.17$ & $12.94 \pm 0.21$ & $1.20 \pm 0.11$ \\
\hline $\mathrm{BPNS}_{7}$ & $23.90 \pm 0.43$ & $12.88 \pm 0.31$ & $1.27 \pm 0.13$ \\
\hline
\end{tabular}

*Average of three determinations \pm standard Deviation

Determination of size of niosomes, zeta potential, entrapment efficiency and number of niosomes

Determination of size of the niosomes and size distribution of niosomes formed is significant [41]. The average niosomes size was in between 187-245 nm. Concentration of the cholesterol and length of the surfactant alkyl chain influences the size of the niosomes. Longer the chain length smaller the size of niosomes.

The particle size increased because of an increase in the width of lipid bilayers when cholesterol concentration increases to have a positive effect on the bilayer characteristics such as rigidness and hydrophobicity. 
The Polydispersity index values are inside the allowable limits for all the proniosomal formulations, indicating enhanced homogeneity which is to judge unimodal size distribution. The lower the Polydispersity index value, the more monodispersed the dispersion, which is less than 0.35 for all the proniosomal formulations.

A zeta potential value for all proniosomal formulations was between-48.4 and $+52.9 \mathrm{mV}$.

Ultra-filtration procedure is employed to determine the amount of drug entrapped as the procedure doesn't involve any dilution levels as in chromatographic techniques i.e., column and dialysis. Very high encapsulation efficiency results were exhibited for niosomes prepared from Spans, which is based on the following explanation that is, the more the lipophilic part of drug molecule the better the drug accommodation would be.

Entrapment efficiency for all proniosomal formulations is in the range of $75 \%$ and $88 \%$ whose values are directly proportional to cholesterol concentration. Better the values, lesser the drug leakage from the rigid and compact stable bilayers due to increased hydrophobic interactions. But extremely high content of cholesterol leads to a decrease in entrapment of drugs within niosomes which is because of the disruption of rigid hydrophobic bilayers.
Spans 20 and 80 have low phase transition temperature thus leading to bilayers, which are low in permeation compared to Span 60 [42] Phase transition temperature and availability of lipophilic ambience also play a major role in entrapment efficiency. Span 40 and span 60 which are solids in normal room temperature, have relatively elevated phase transition temperatures hence the highest drug entrapment. The lower entrapment of drugs when span 80 with unsaturated alkyl chain is used though it has the same head group as span 60 is because of presence of double bond in the chemical structure unlike span 60 . Same kind of pattern is followed by Tween 80 among other tweens $(20$ 40 and 60) which fortifies the fact that the tendency towards aqueous and non-aqueous phase plays an important part in release of the drug. Proniosome formulations prepared using Tween 20, 40, 60 and 80 showed relatively low drug encapsulation against prepared using Spans, which is due to insufficient amount of cholesterol; that is, niosomes are obtained only when the cholesterol content is above $33.33 \mathrm{~mol} \%$ [43]. Amount of cholesterol directly influences the encapsulation of the drug with reverse action on niosome size.

The more the number of niosomes formed from proniosomes in the GI tract upon hydration, the better the dosage form can be speculated. Among various formulations, the formulation with the following code $\mathrm{BPNS}_{4}$ demonstrates good number of niosomes. The results of all above-mentioned physicochemical parameters are represented in table 3 for various proniosomal formulations.

Table 3: Physico-chemical characterization of various provesicular systems of bazedoxifene acetate

\begin{tabular}{|c|c|c|c|c|c|}
\hline Formulation code & Particle size $^{*}$ & Polydispersity index & Zeta potential $^{*}$ & \% Drug entrapped* & Number of vesicles $/ \mathrm{mm}^{3} \times 10^{3}$ \\
\hline $\mathrm{BPNS}_{1}$ & $234 \pm 12$ & 0.348 & $48.4 \pm 3.2$ & $78.2 \pm 4.5$ & 3.12 \\
\hline $\mathrm{BPNS}_{2}$ & $209 \pm 13$ & 0.183 & $50.6 \pm 3.7$ & $75.9 \pm 4.3$ & 3.00 \\
\hline $\mathrm{BPNS}_{3}$ & $187 \pm 16$ & 0.100 & $52.9 \pm 2.4$ & $88.6 \pm 3.2$ & 4.21 \\
\hline $\mathrm{BPNS}_{4}$ & $219 \pm 21$ & 0.254 & $49.9 \pm 3.1$ & $87.3 \pm 2.5$ & 4.50 \\
\hline $\mathrm{BPNS}_{5}$ & $231 \pm 27$ & 0.310 & $50.8 \pm 1.1$ & $84.1 \pm 3.5$ & 3.98 \\
\hline $\mathrm{BPNS}_{6}$ & $211 \pm 11$ & 0.255 & $51.9 \pm 4.3$ & $81.5 \pm 4.7$ & 3.45 \\
\hline $\mathrm{BPNS}_{7}$ & $245 \pm 29$ & 0.309 & $52.7 \pm 2.6$ & $79.8 \pm 1.3$ & 3.22 \\
\hline
\end{tabular}

* Average of three determinations \pm standard Deviation

\section{In vitro dissolution study}

The percent drug release was outstandingly more for almost all proniosomal powder formulations when measured against control for all proniosomal formulations in the respective dissolution medium. The amount of bazedoxifene acetate released from proniosomes was ranging between $70 \%$ and $92 \%$ in $60 \mathrm{~min}$ and was remarkably higher compared to control, which is $8 \%$ for same time period, as shown in fig. 2 . The results are represented in table 4.

Dissolution efficiency of drugs has drastically increased when the drug is delivered in the form of proniosome systems, which might be attributed to the improved solubility of the drug by non-ionic surfactant molecules or transformation of the crystalline state of the drug to an amorphous state [44].

Table 4: The amount of bazedoxifene acetate released from proniosomes was ranging between $70 \%$ and $92 \%$ in 60 min and was remarkably higher compared to control which is $\mathbf{8 \%}$ for same time period

\begin{tabular}{|c|c|c|c|c|c|c|c|c|}
\hline \multirow{2}{*}{$\begin{array}{l}\text { Time } \\
\text { (min) }\end{array}$} & \multicolumn{8}{|c|}{ Cumulative percent drug released ${ }^{*}$} \\
\hline & Control & BPNS $_{1}$ & BPNS $_{2}$ & BPNS $_{3}$ & BPNS $_{4}$ & BPNS $_{5}$ & BPNS $_{6}$ & BPNS $_{7}$ \\
\hline 0 & $0.00 \pm 0.00$ & $0.00 \pm 0.00$ & $0.00 \pm 0.00$ & $0.00 \pm 0.00$ & $0.00 \pm 0.00$ & $0.00 \pm 0.00$ & $0.00 \pm 0.00$ & $0.00 \pm 0.00$ \\
\hline 5 & $0.00 \pm 0.00$ & $0.00 \pm 0.00$ & $0.00 \pm 0.00$ & $0.00 \pm 0.00$ & $0.00 \pm 0.00$ & $0.00 \pm 0.00$ & $0.00 \pm 0.00$ & $0.00 \pm 0.00$ \\
\hline 10 & $4.25 \pm 0.44$ & $43.25 \pm 0.90$ & $45.50 \pm 0.74$ & $48.75 \pm 0.39$ & $46.25 \pm 0.32$ & $42.50 \pm 0.85$ & $41.25 \pm 0.14$ & $40.25 \pm 0.81$ \\
\hline 30 & $6.27 \pm 0.31$ & $68.74 \pm 0.21$ & $65.75 \pm 0.60$ & $72.02 \pm 0.57$ & $68.51 \pm 0.47$ & $52.24 \pm 0.17$ & $52.23 \pm 0.49$ & $49.97 \pm 0.41$ \\
\hline 60 & $8.06 \pm 0.29$ & $82.87 \pm 0.11$ & $80.12 \pm 0.42$ & $91.92 \pm 0.79$ & $85.14 \pm 0.51$ & $70.78 \pm 0.19$ & $74.52 \pm 0.99$ & $71.50 \pm 0.74$ \\
\hline 90 & $12.10 \pm 0.57$ & $88.58 \pm 0.14$ & $90.31 \pm 0.32$ & $93.68 \pm 0.63$ & $91.36 \pm 0.40$ & $86.92 \pm 0.14$ & $84.68 \pm 0.72$ & $81.14 \pm 0.39$ \\
\hline 120 & $16.17 \pm 0.64$ & $94.06 \pm 0.86$ & $96.55 \pm 0.21$ & $98.19 \pm 0.67$ & $97.86 \pm 0.57$ & $93.64 \pm 0.44$ & $91.64 \pm 0.61$ & $88.84 \pm 0.58$ \\
\hline
\end{tabular}

*Average of three determinations \pm Standard Deviation

\section{Scanning electron microscopy}

Scanning electron microscopy images as in fig. 3 aids in studying the surface morphology of the proniosome powders along with drug and carriers.
Non-existence of crystalline drug structure in proniosome preparations specified the conversion of drug to molecular or amorphous state from crystalline form. And also, maltodextrin porous structure was not visible in formulations because of settling of spans on the surface of carrier. 


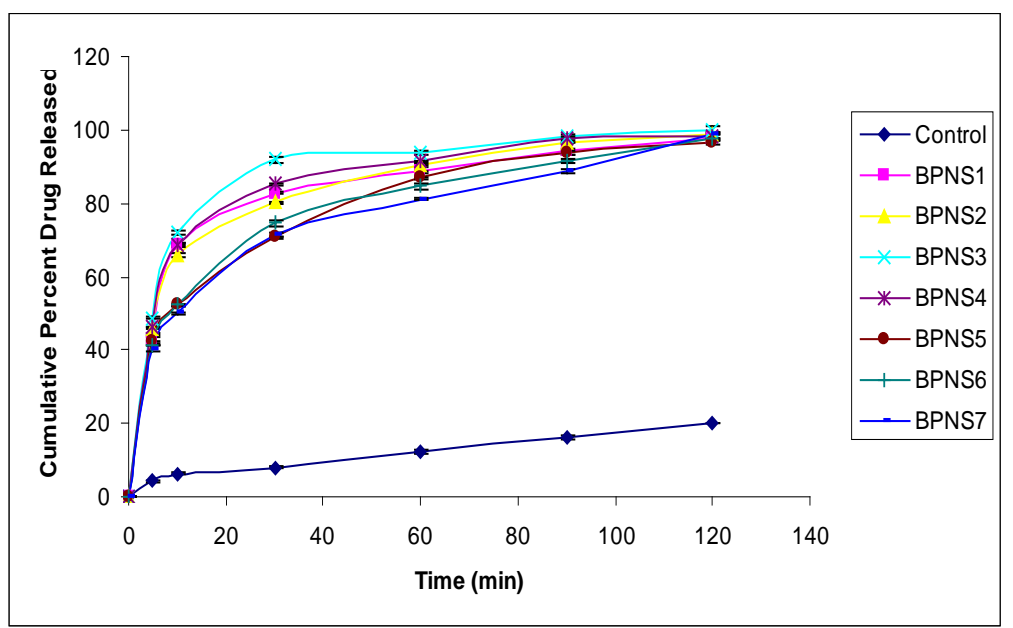

Fig. 2: Cumulative percent drug release versus time plots of bazedoxifene acetate in pure Form and proniosomal formulations using span 40

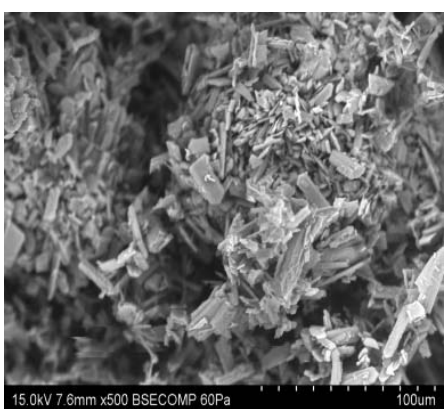

(a)

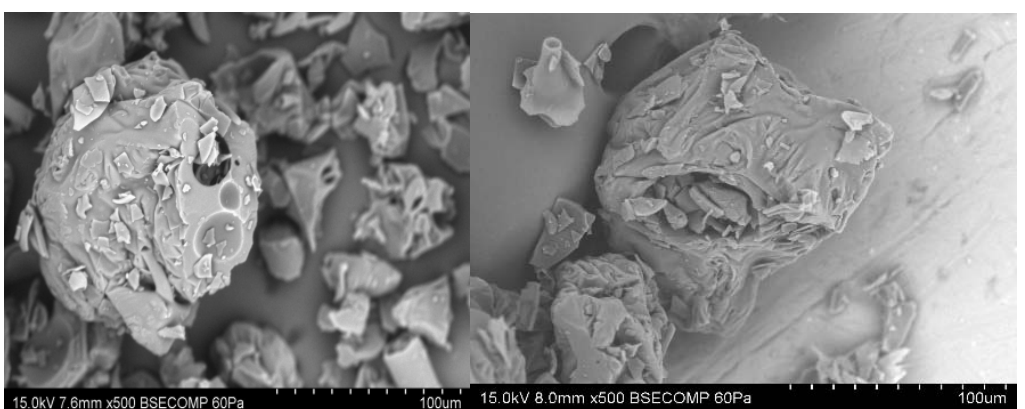

(b)

(c)

Fig. 3: SEM Images of (a) Bazedoxifene acetate (b) Proniosome powder (c) Maltodextrin

\section{Transmission electron microscopy}

Transmission electron microscopy is a microscopic technique commonly used for the analysis of materials on the nanoscale. Because it uses electrons, which have a shorter wavelength than light, it is capable of achieving resolution a thousand times better than that can be achieved with a light microscope [45].

Transmission Electron Microscopy analysis confirms the spherical shape of niosomes formed after hydration of proniosomal systems, as shown in fig. 4. The image analysis showed that the niosomes were surrounded by homogeneous shading; this suggests that formed niosomes resembled the drug-enriched core model.

\section{Differential scanning calorimetry}

In differential scanning calorimetry thermograph of proniosome formulations, endotherm peak fades away or vanishes around melting point, which is clearly visible in pure drug differential scanning calorimetry thermograph indicating the metamorphosis of crystalline state in pure drug to amorphous state in formulations as shown in fig. $5 a$ and $5 b$.

\section{Powder X-RAY diffractometry}

Reduction in the intensity or absence of characteristic drug peaks in the proniosome optimized formulations compared to pure drug Bazedoxifene acetate further confirms the amorphization of the drug by PXRD analysis as shown in fig. $6 \mathrm{a}$ and $6 \mathrm{~b}$.

\section{FT-IR analysis}

FTIR spectrum of proniosomal formulation without any extra peaks, when compared to pure drug spectrum, extrapolates the lack of chemical interaction as indicated in fig.7a, 7b, 7c.

Based on the various evaluation parameter results, the optimized formulation further proceeded for stability, ex vivo and in vivo studies.

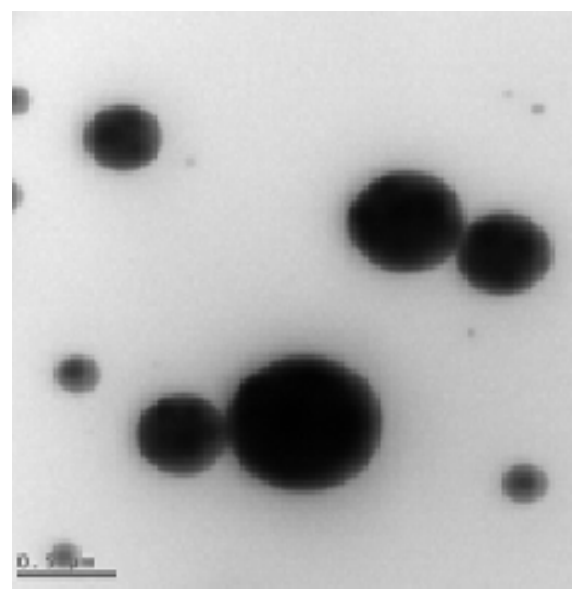

Fig. 4: TEM images of bazedoxifene acetate proniosome powder 


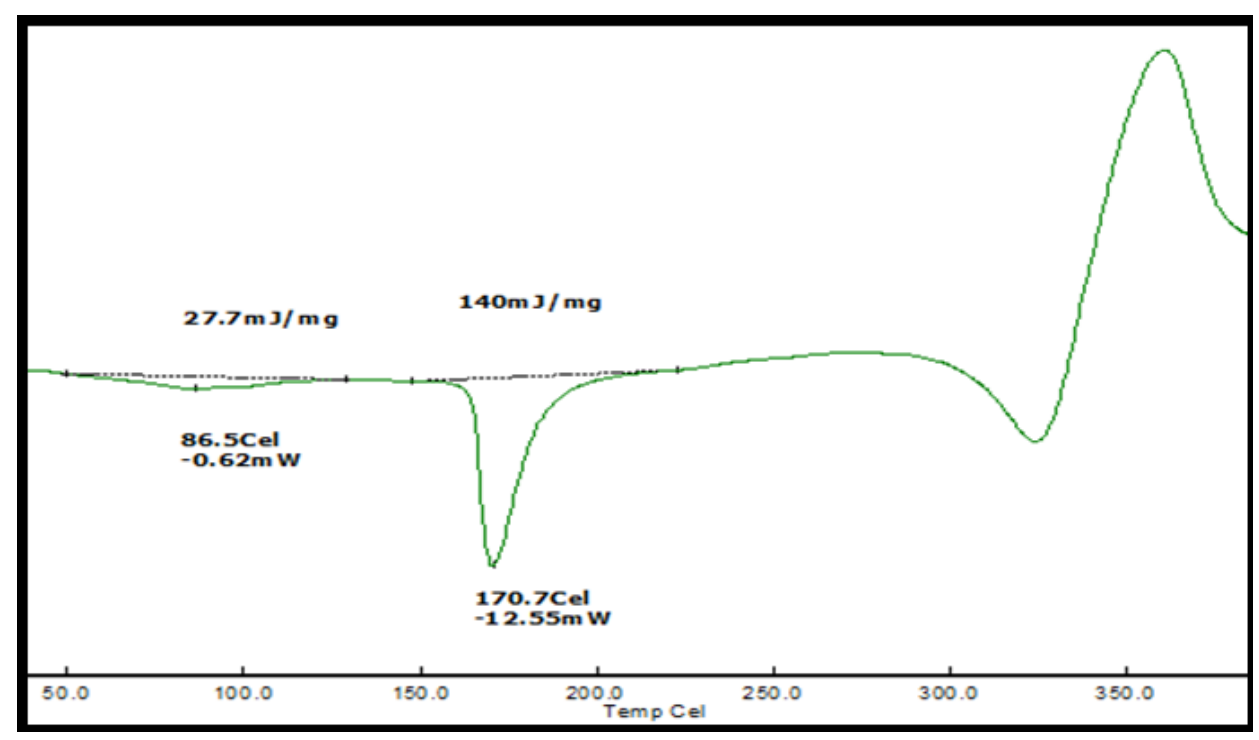

Fig. 5a: DSC of bazedoxifene acetate

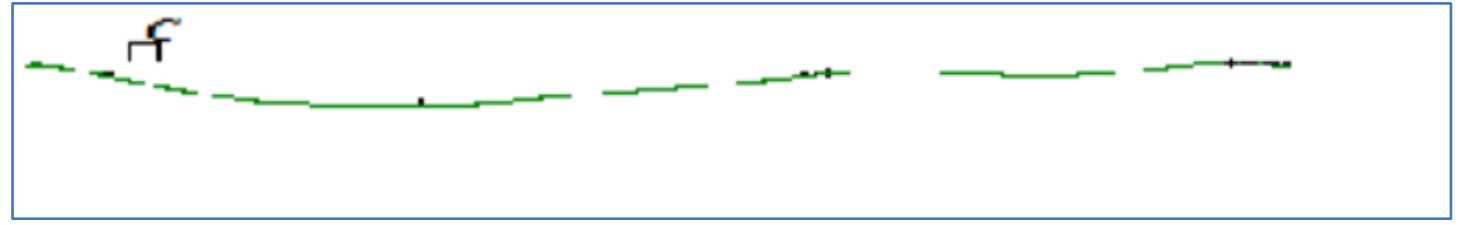

Fig. 5b: DSC of optimized formulation of $\mathrm{BPSN}_{3}$

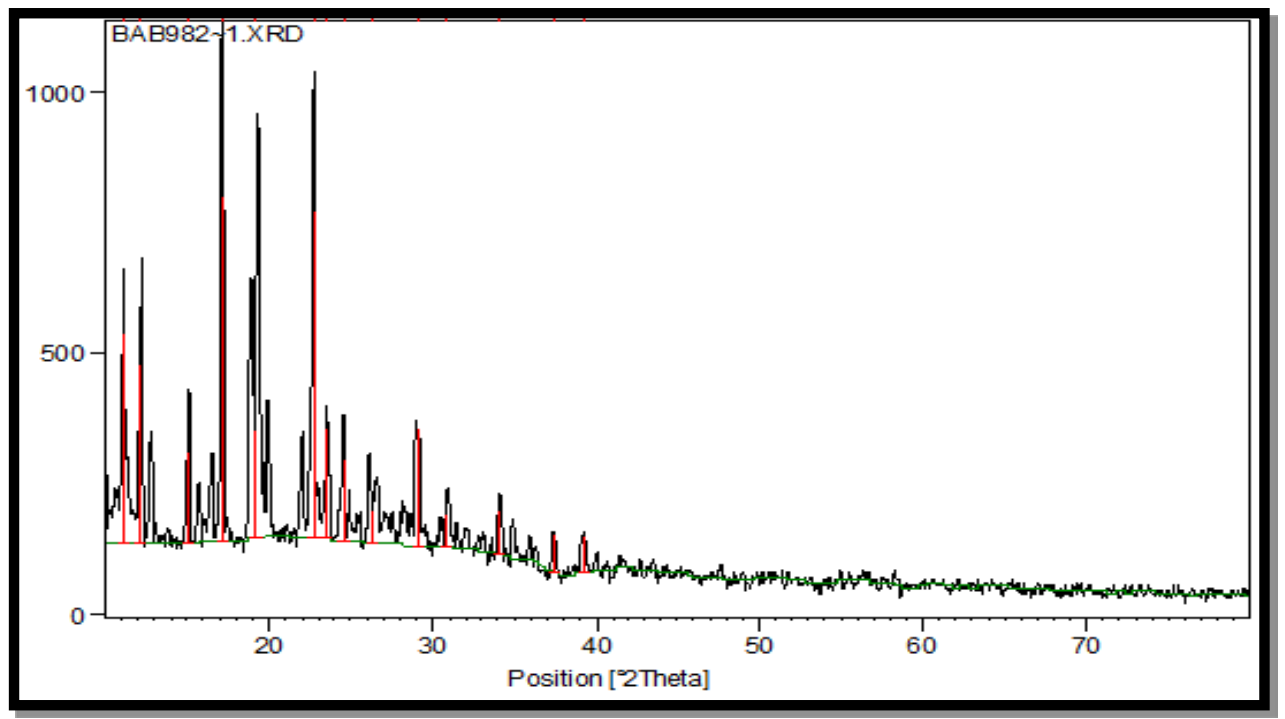

Fig. 6a: PXRD of bazedoxifene acetate

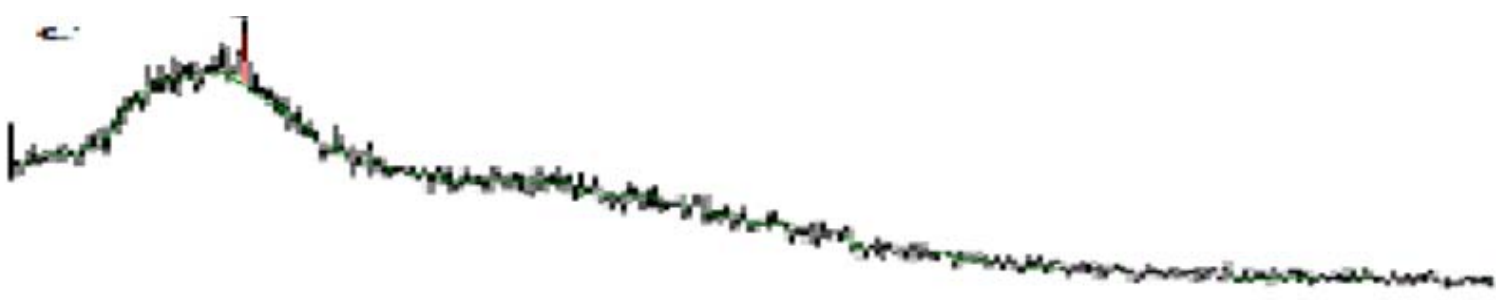

Fig. 6b: PXRD of optimized formulation of BPNS 3 


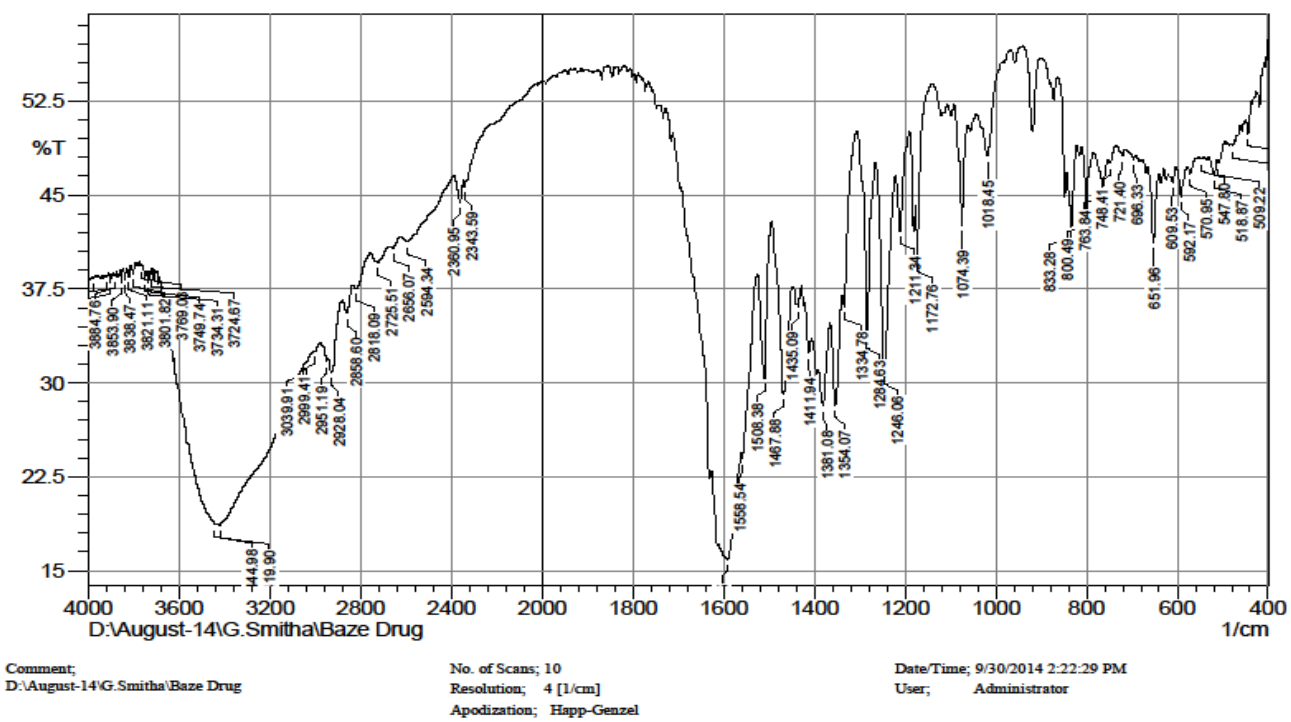

Fig. 7a: IR spectrum of bazedoxifene acetate

ФSHIMADZU

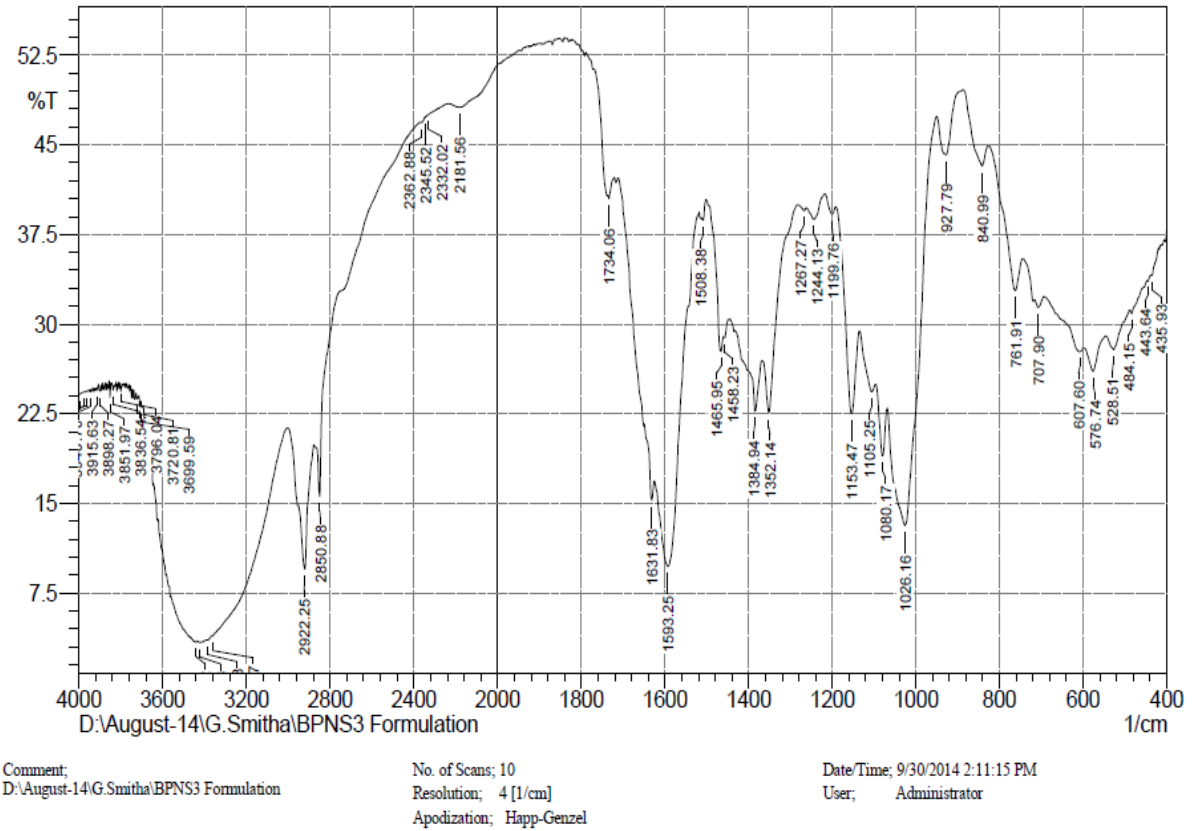

Fig. 7b: IR spectrum of BPNS ${ }_{3}$ formulation

\section{Stability studies}

Shelf life for the drug under stated conditions is dictated by the amount of drug retained within the niosomes. Physical appearance, size of the niosomes, percentage retention and ex vivo permeation across rat intestine of the respective drug after storing at $24{ }^{\circ} \mathrm{C}$ and $4{ }^{\circ} \mathrm{C}$ temperature for 6 mo are investigated in the stability studies for optimized formulation. Samples were pulled out at specified time points and proniosomal powders were restored to form niosomal dispersions. Initially, the powder was found to be dry, free-flowing in nature without any lumps, after contact with water lead to the formation of niosomes immediately. Under optical microscope, drug crystallization was also not observed. No change in the size of the particles and size distribution represents proniosomal formulation stability. Significantly more amount of drug retention was observed at all sampling points. And also, ex vivo permeation study results indicated not much variation in the amount of drug permeated, flux, permeability coefficient and enhancement ratio values when compared to initial. In contrast, the formulation was destabilized at room temperature $\left(24^{\circ} \mathrm{C}\right)$, resulting in larger niosome size, drug leakage with less entrapment efficiency with time and chaotic ex vivo permeation results.

The stability studies as represented in table 5 suggest that the proniosomal powder was comparatively more stable when stored at refrigerated conditions $\left(4^{\circ} \mathrm{C}\right)$ that at room temperature $\left(24^{\circ} \mathrm{C}\right)$. 


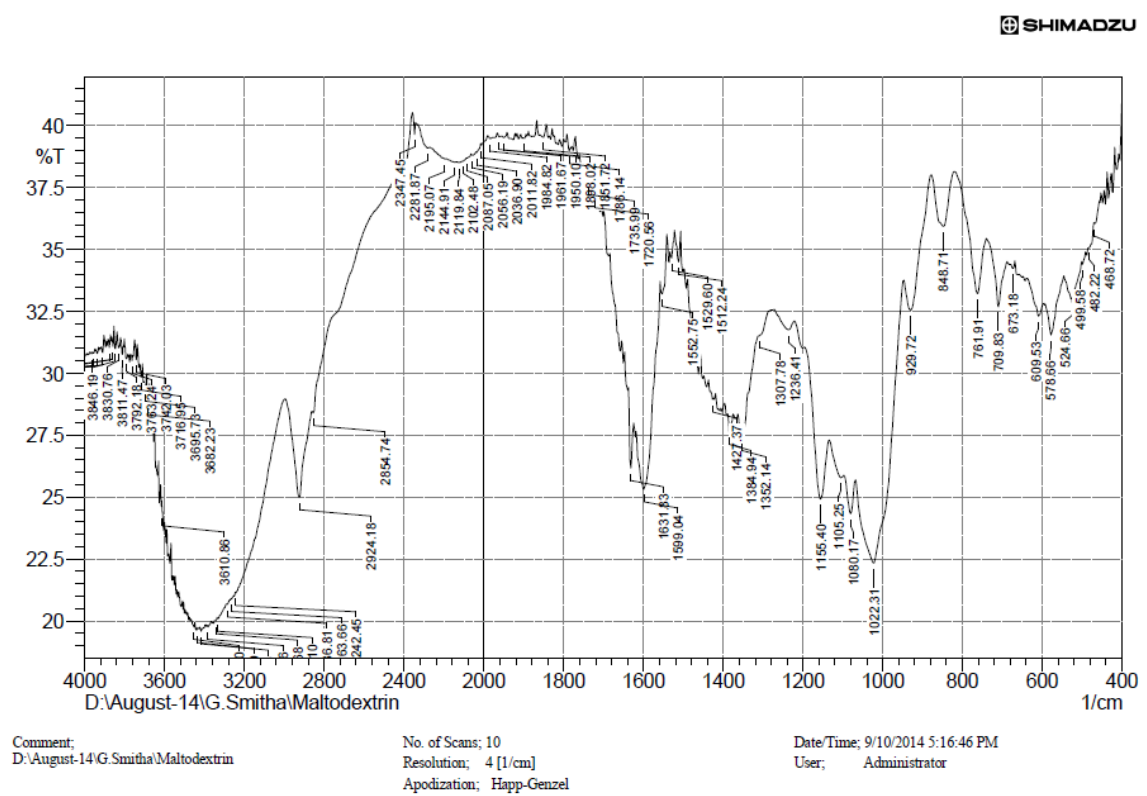

Fig. 7c: IR spectrum of maltodextrin

Table 5: Stability study data for optimized formulation $\left(\mathrm{BPNS}_{3}\right)$

\begin{tabular}{|c|c|c|c|c|c|c|}
\hline Stability evaluation parameters* & Initial & 30d & 60d & 90d & 120d & 180d \\
\hline Particle Size & $187 \pm 16$ & $208 \pm 13$ & $201 \pm 16$ & $198 \pm 14$ & $202 \pm 18$ & $208 \pm 11$ \\
\hline$\%$ Retention of drug & $88.6 \pm 3.2$ & $92.0 \pm 2.2$ & $90.0 \pm 4.0$ & $88.0 \pm 1.9$ & $92.1 \pm 3.6$ & $88.6 \pm 2.7$ \\
\hline $\begin{array}{l}\text { Cumulative amount drug permeated } \\
(\mu \mathrm{g} / \mathrm{cm} 2)\end{array}$ & $228.6 \pm 28$ & $219.8 \pm 24$ & $223.6 \pm 18$ & $218.7 \pm 19$ & $224.6 \pm 25$ & $232.8 \pm 26$ \\
\hline
\end{tabular}

*Average of three determinations \pm standard Deviation

\section{Ex vivo absorption study using rat intestine}

Permeation across the gastrointestinal tract is also a rate-limiting step for the absorption of drug other than dissolution. Therefore, $e x$ vivo permeation studies were performed using the rat intestine. Since a great number of available active pharmaceutical ingredients get absorbed in vivo from the small intestine it is more relevant to use the rat tissue [46]. Hence, we have used ileum portion to evaluate the potential of proniosome powder formulations for increasing the permeation of drugs across the intestine barrier.

The amount of drug permeated from proniosomal systems for bazedoxifene acetate has enhanced when compared with respective control within a period of $2 \mathrm{~h}$ as shown in the graphical image of fig. 8. The flux values also improved for proniosomal system when compared with control. The ER above 1 shows enhanced permeation of proniosome when compared with control.

Thus, the remarkable improvement in the permeation can be owed to the combination of several mechanisms:

1. Presence of nonionic surfactant could obviate the barrier function due to the fluidization of the intercellular lipid bilayer,

2. Better membrane contact and permeation enhancement property of the non-ionic surfactants might have led to altered permeability characteristics of the membrane, which otherwise result in improved partitioning of the drug into the bilayer,

3. Direct transfer of niosomes across the epithelial membrane.

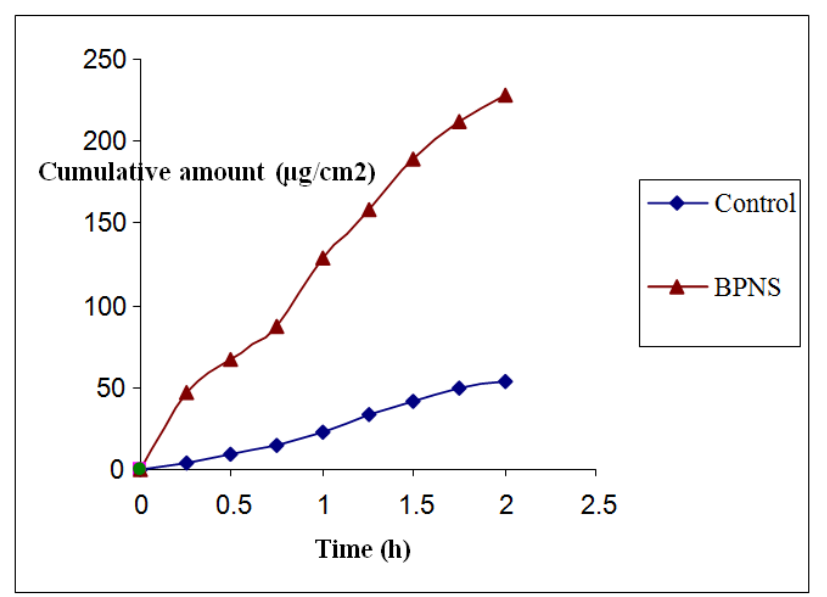

Fig. 8: Ex vivo permeation of Bazedoxifene acetate across rat intestine from provesicular systems (mean \pm standard deviation, $n=6$ ) 


\section{In vivo bioavailability study}

\section{Pharmacokinetic study}

The average serum concentration vs time intervals after orally administering an optimized formulation of bazedoxifene acetate proniosome powder in comparison against control (pure drug at a dose of $10 \mathrm{mg} / \mathrm{kg}$ ) are shown. Various pharmacokinetic parameters are calculated and represented in table 6. Results obtained show a higher Cmax and Tmax for proniosomes when compared against control. Slower excretion of bazedoxifene acetate drug from proniosomes is evidently the reason for higher mean residence time (MRT) when compared against control. Area under the Curve (AUC) values following oral administration is remarkably more when compared against control, indicating higher systemic exposure, thus overcoming the bioavailability problem; which is raised as a result of increased hepatic metabolism. Relative bioavailability for the drug after giving proniosomes by oral route was found to be more when compared against control with a significant difference of $p<0.001$. Thus, it is proved from the reports that bioavailability of bazedoxifene acetate have been markedly improved from proniosomal systems when compared against control. The permeability and potential uptake of slightly soluble drugs is increased, thus enhancing the bioavailability. Overall improvement in the relative bioavailability (RA) deduces the potential of proniosomes as a suitable carrier for improved oral delivery of bazedoxifene acetate.

Table 6: Pharmacokinetic parameters of bazedoxifene acetate in rats following oral administration of optimized formulation (mean \pm standard deviation, $\mathrm{n}=6$ )

\begin{tabular}{lll}
\hline Pharmacokinetic parameters & Control & BPNS $_{3}$ \\
\hline $\mathrm{C}_{\max }(\mu \mathrm{g} / \mathrm{ml})$ & $0.639 \pm 0.02$ & $0.968 \pm 0.01$ \\
$\mathrm{~T}_{\max }(\mathrm{h})$ & $2.0 \pm 0.00$ & $2.0 \pm 0.00$ \\
$\mathrm{~T}_{1 / 2}(\mathrm{~h})$ & $31.735 \pm 0.663$ & $26.798 \pm 0.3$ \\
$\mathrm{Ke}(\mathrm{h}-1)$ & $0.022 \pm 0.605$ & $0.026 \pm 0.0003$ \\
$\mathrm{AUC}$ & $0-\mathrm{t}\left(\mu \mathrm{g} . \mathrm{h} . \mathrm{ml}^{-1}\right)$ & $23.329 \pm 0.2$ \\
$\mathrm{AUC}_{0-\infty}\left(\mu \mathrm{g} . \mathrm{h} . \mathrm{ml}^{-1}\right)$ & $17.011 \pm 0.264$ & $26.018 \pm 0.3$ \\
$\mathrm{MRT}_{0-\infty}(\mathrm{h})$ & $19.346 \pm 0.242$ & $20.064 \pm 0.09$ \\
$\mathrm{RA}$ & $17.475 \pm 0.194$ & $1.35 \pm 0.02$ \\
\hline
\end{tabular}

\section{Ex vivo/in vivo correlation}

The $\mathrm{r}^{2}$ values are closer to linear for optimized formulation of the drug when the graph is plotted between the AUC of In vivo and ex vivo concentration at different time points, thus concluding a correlation as shown in fig. 9.

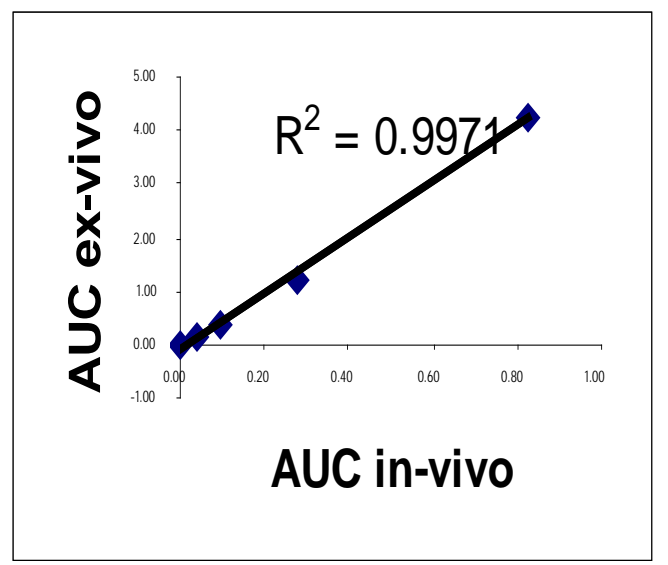

Fig. 9: Ex vivo/In vivo correlation graph of $\mathrm{BPNS}_{3}$

\section{CONCLUSION}

Bazedoxifene acetate proniosomes were prepared by the slurry method using maltodextrin as a carrier at varying ratios of spans and cholesterol. The formulation containing 0.6:0.4 of span 40 and cholesterol was optimized based on the physicochemical characterization and dissolution studies. The in vivo pharmacokinetic studies reveal the potential of proniosomes as suitable carriers for poorly soluble drugs. The results of this study clearly indicate the improvement in intestinal absorption and oral bioavailability of bazedoxifene acetate. The improved delivery of niosome entrapped drugs is mediated by vesicle adsorption onto the cell surface, followed by endocytosis. A particularly attractive feature of this study is that it may be applied to preparations for oral administration i.e., a proniosome composition may be placed inside a capsule, which is then swallowed whole. Depending on the design of the capsule, the contents will be released somewhere in the gastrointestinal tract to form niosomes in vivo. The drug remains protected within the layers of the niosomes. It has been suggested that protecting a poorly absorbed, labile drug in this manner could help absorption. In this connection, it has been noted that niosomes can form, irrespective of the ionic strength of the aqueous environment, in the range $\mathrm{pH} 3.2$ to 8.6. It is assumed that any "free" drug remaining in the aqueous environment after spontaneous niosome formation is non-toxic and need not be removed. A further in vivo study in humans fortifies the improved oral delivery of bazedoxifene acetate prior to human use.

\section{ACKNOWLEDGEMENT}

The authors are grateful to MSN labs, Hyderabad, for providing the gift sample of bazedoxifene acetate. The authors are thankful to Lipoid, Germany for the generous gift of Phospholipon 90H. The authors acknowledge Management, Principal of Sri Venkateshwara college of Pharmacy, Surabhi educational society for providing the necessary facilities to carry out the work.

\section{FUNDING}

Nil

\section{AUTHORS CONTRIBUTIONS}

All the authors have contributed equally.

\section{CONFLICT OF INTERESTS}

The authors report no conflicts of interest.

\section{REFERENCES}

1. Swati S, George M, Lincy J. Improvement in the solubility of poor water-soluble drugs by solid dispersion. Int J Pharm Investig 2012;2:12-7.

2. Smitha G, Areefulla SH, Swamy PV. Enhancement of in vitro dissolution characteristics of nifedipine by co-grinding technique. Int J Pharm Chem Sci 2012;1:1279-85.

3. Mullins JD, Macek TJ. Some pharmaceutical properties of novobiocin. J Am Pharm Assoc 1960;49:245-8.

4. Atkinson RM, Bedford C, Child KJ, Tomich EG. Effect of particle size on blood griseofulvin-levels in man. Nature 1962;193:5889.

5. O'Driscoll CM, Griffin BT. Biopharmaceutical challenges associated with drugs with low aqueous solubility-the 
potential impact of lipid-based formulations. Adv Drug Delivery Rev 2008;60:617-24.

6. Tang B, Cheng G, Gu JC, Xu CH. Development of solid selfemulsifying drug delivery systems: preparation techniques and dosage forms. Drug Discovery Today 2008;13:606-12.

7. Jha AK, Kumar R, Kumar S, Jha SS. Vesicular system carrier for drug delivery. Der Pharm Sin 2011;2:192-202.

8. Schreier H, Bouwstra J. Liposomes and niosomes as topical drug carriers: dermal and transdermal drug delivery. J Controlled Release 1994;30:1-15.

9. Ijeoma FU, Vyas SP. Non-ionic surfactant based vesicles (niosomes) in drug delivery. Int J Pharm 1998;172:33-70.

10. Deepthi Annakula, Madhukar Rao Errabelli, Raju Jukanti, Suresh Bandari, Prabhakar Reddy Veerareddy. Provesicular drug delivery systems: an overview and appraisal. Arch Appl Sci Res 2010;2:135-46.

11. Sarala Y, Natarajan V, Veeran GK, Zhijun W, Manish I, Guru VB. Proliposomes as a drug delivery system to decrease the hepatic first-pass metabolism: case study using a model drug. Eur J Pharm Sci 2014;64:26-36.

12. Yasam VR, Jakki SL, Natarajan J, Kuppusamy G. A review on novel vesicular drug delivery: proniosomes. Drug Delivery 2014;21:243-9.

13. Gangadharappa HV, Gangadhar V, Nagashubha B. Approaches for improvement of vesicular system-pro-vesicular drug delivery. Am J Pharm Tech Res 2014;4:16-57.

14. Bayindir ZS, Yuksel N. Provesicles as novel drug delivery systems. Curr Pharm Biotechnol 2015;16:344-64.

15. Hu C, Rhodes DG. Proniosomes: a novel drug carrier preparation. Int J Pharm 1999;185:23-35.

16. Gannu PK, Pogaku R. Nonionic surfactant vesicular systems for effective drug delivery-an overview. Acta Pharm Sinica B 2011;1:208-19.

17. Abd-Elbary A, El-laithy HM, Tadros MI. Sucrose stearate-based proniosome-derived niosomes for the nebulisable delivery of cromolyn sodium. Int J Pharm 2008;357:189-98.

18. Sankar V, Ruckmani K, Durga S, Jailani S. Proniosomes as drug carriers. Pak J Pharm Sci 2010;23:103-7.

19. Akhilesh D, Hazel G, Kamath JV. Proniosomes-a propitious Provesecular drug carrier. Int J Pharm Pharm Sci Res 2011;1:98-103.

20. Jaime Kulak Junior, Carolina Aguiar Moreira Kulak, Hugh S Taylor. SERMs in the prevention and treatment of postmenopausal osteoporosis: an update. Arq Bras Endocrinol Metabol 2010;54:200-5.

21. Hadji P. The evolution of selective estrogen receptor modulators in osteoporosis therapy. Climacteric 2012;15:513-23.

22. Chines AA, Komm BS. Bazedoxifene acetate: a novel selective estrogen receptor modulator for the prevention and treatment of postmenopausal osteoporosis. Drugs Today (Barc) 2009;45:507-20.

23. Diana MS, Stefanie CN. Bazedoxifene: an investigational selective estrogen receptor modulator for the treatment and prevention of osteoporosis in postmenopausal women. Formulary 2011;46:159-76.

24. Ronkin S, Northington R, Baracat E, Nunes MG, Archer DF, Constantine G, et al. Endometrial effects of bazedoxifene acetate, a novel selective estrogen receptor modulator, in postmenopausal women. Obstet Gynecol 2005;105:1397404.

25. Nagasamy Venkatesh D, Swetha Priyanka V, Tulasi K, Kalyani K, Sheik Abid Ali, Harikrishna J. Proniosomes: a superior drug delivery system. Int J Pharm Sci Drug Res 2014;6:178-82.
26. Bangham AD, Standish MM, Watkins JC. Diffusion of univalent ions across the lamellae of swollen phospholipids. J Mol Biol 1965;13:238-52.

27. Staniforth J. Powder flow. In: M Aulton. ed. Pharmaceutics, The Science of Dosage form Design. second ed. Churchill Livingstone: Longman Group Edinburgh; 2002. p. 197-210.

28. Lieberman HA, Lachman L, Schwartz JB. Pharmaceutical dosage forms: Tablets, Marcel Dekker, New York; 1990. p. 201-43.

29. Carr RL. Evaluation of flow properties of solids. Chem Eng 1965;72:163-8.

30. Manjunath K, Venkateswarlu V. Pharmacokinetics, tissue distribution and bioavailability of clozapine solid lipid nanoparticles after intravenous and intraduodenal administration. J Controlled Release 2005;107:215-28.

31. Jukanti R, Sheela S, Bandari S, Veerareddy PR. Enhanced bioavailability of exemestane via proliposomes based transdermal delivery. J Pharm Sci 2011;100:3208-22.

32. Smitha G. Determination of bazedoxifene acetate in bulk with the aid of Uv-spectroscopy: development and validation. Int J Pharm Tech Res 2014;7:641-7.

33. Blazek Welsh AI, Rhodes DG. SEM imaging predicts quality of niosomes from maltodextrin-based proniosomes. Pharm Res 2001;18:656-61.

34. Mohamed S El-Ridy, Alia A Badawi, Marwa M Safar, Amira M Mohsen. Niosomes as a novel pharmaceutical formulation encapsulating the hepatoprotective drug silymarin. Int J Pharm Pharm Sci 2012;4:549-59.

35. Pradip KG, Rita JM, Manish LU, Rayasa SRM. Design and development of microemulsion drug delivery system of acyclovir for improvement of oral bioavailability. AAPS PharmSciTech 2006;7:E1-E5.

36. Gandra S, Sheelam SCR, Maddela R, Reddymalla P, Bakshi V, Jukanti R. Bazedoxifene acetate quantification in rat serum with the aid of RP-HPLC: method development and validation. World J Pharm Sci 2015;3:2357-63.

37. Nel I, Gauler TC, Eberhardt WE, Nickel AC, Schuler M, Thomale $\mathrm{J}$, et al. Formation and repair kinetics of Pt- $(\mathrm{GpG}) \mathrm{DNA}$ adducts in extracted circulating tumour cells and response to platinum treatment. Br J Cancer 2013;109:1223-9.

38. Almira I Blamek Welsh, David G Rhodes. Maltodextrin-based proniosomes. Pharm Sci 2001;3:1-8.

39. Gupta A, Prajapati SK, Singh M, Balamurugan M. Proniosomal powder of captopril: formulation and evaluation. Mol Pharm 2007;4:596-9.

40. Solanki AB, Parikh JR, Parikh RH. Formulation and optimization of piroxicam proniosomes by 3-factor, 3-level box-behnken design. AAPS PharmSciTech 2007;8:E1-E7.

41. Plessis J, Ramachandran C, Weiner N, Miller DG. The influence of particle size of liposomes on deposition of drug into skin. Int J Pharm 1991;103:277-82.

42. Namdeo A, Jain NK. Niosomal delivery of 5-fluorouracil. J Microencapsul 1999;16:731-40.

43. Uchegbu IF, Florence AT. Non-ionic surfactant vesicles (niosomes): physical and pharmaceutical chemistry. Adv Coll Interf Sci 1995;58:1-55.

44. Praveen SH, Kumaresh SS, Guru VB. Proliposomes of exemestane for improved oral delivery: formulation and in vitro evaluation using PAMPA, Caco-2 and rat intestine. Int J Pharm 2009;380:96-104.

45. Bradbury S, Joy DC, Ford BJ. Transmission electron microscope (TEM). Encyclopedia Britannica; 2011.

46. Cornaire G, Woodley J, Hermann P, Cloarec A, Arellano C, Houin G. Impact of excipients on the absorption of P-glycoprotein substrates in vitro and in vivo. Int J Pharm 2004;278:119-31. 